\title{
Validation of the Spanish Version of the Yale Food Addiction Scale 2.0 (YFAS 2.0) and Clinical Correlates in a Sample of Eating Disorder, Gambling Disorder, and Healthy Control Participants
}

\section{OPEN ACCESS}

Edited by: Andreas Stengel, Charité Universitätsmedizin Berlin, Germany

Reviewed by:

Jörn von Wietersheim, Universität UIm, Germany Özgür Albayrak,

Hannover Medical School, Germany

*Correspondence: Susana Jiménez-Murcia sjimenez@bellvitgehospital.cat Fernando Fernández-Aranda ffernandez@bellvitgehospital.cat

Specialty section: This article was submitted to Psychosomatic Medicine, a section of the journal Frontiers in Psychiatry

Received: 24 January 2018 Accepted: 03 May 2018 Published: 25 May 2018

Citation:

Granero R, Jiménez-Murcia S, Gearhardt AN, Agüera Z, Aymamí N, Gómez-Peña M, Lozano-Madrid M, Mallorquí-Bagué N, Mestre-Bach G, Neto-Antao MI, Riesco N, Sánchez I, Steward T, Soriano-Mas C,

Vintró-Alcaraz C, Menchón JM,

Casanueva FF, Diéguez $C$ and Fernández-Aranda F (2018) Validation of the Spanish Version of the Yale Food Addiction Scale 2.0 (YFAS 2.0) and Clinical Correlates in a Sample of Eating Disorder, Gambling Disorder, and Healthy Control Participants.

Front. Psychiatry 9:208.

doi: 10.3389/fpsyt.2018.00208
Roser Granero ${ }^{1,2}$, Susana Jiménez-Murcia ${ }^{1,3,4^{*}}$, Ashley N. Gearhardt ${ }^{5}$, Zaida Agüera ${ }^{1,3}$, Neus Aymamí ${ }^{3}$, Mónica Gómez-Peña ${ }^{3}$, María Lozano-Madrid ${ }^{1,3}$, Núria Mallorquí-Bagué ${ }^{1,3}$, Gemma Mestre-Bach ${ }^{1,3}$, Maria I. Neto-Antao ${ }^{3}$, Nadine Riesco $^{3}$, Isabel Sánchez ${ }^{3}$, Trevor Steward ${ }^{1,3}$, Carles Soriano-Mas ${ }^{3,6}$, Cristina Vintró-Alcaraz ${ }^{3}$, José M. Menchón ${ }^{3,4,6}$, Felipe F. Casanueva ${ }^{1,7}$, Carlos Diéguez ${ }^{1,8}$ and Fernando Fernández-Aranda ${ }^{1,3,4 *}$

${ }^{1}$ Ciber Fisiopatología Obesidad y Nutrición, Instituto Salud Carlos III, Barcelona, Spain, ${ }^{2}$ Departament de Psicobiologia i Metodologia, Universitat Autònoma de Barcelona, Barcelona, Spain, ${ }^{3}$ Department of Psychiatry, University Hospital of Bellvitge-IDIBELL, Barcelona, Spain, ${ }^{4}$ Department of Clinical Sciences, School of Medicine and Health Sciences, University of Barcelona, Barcelona, Spain, ${ }^{5}$ Department of Psychology, University of Michigan, Ann Arbor, MI, United States, ${ }^{6}$ ClBER Salud Mental, Instituto Salud Carlos III, Barcelona, Spain, ${ }^{7}$ Laboratory of Molecular and Cellular Endocrinology, Research Area, Complejo Hospitalario Universitario de Santiago de Compostela, A Coruña, Spain, ${ }^{8}$ Department of Physiology, CIMUS, University of Santiago de Compostela-Instituto de Investigación Sanitaria, Santiago de Compostela, Spain

Aims: Due to the increasing evidence of shared vulnerabilities between addictive behaviors and excessive food intake, the concept of food addiction in specific clinical populations has become a topic of scientific interest. The aim of this study was to validate the Yale Food Addiction Scale (YFAS) 2.0 in a Spanish sample. We also sought to explore food addiction and its clinical correlates in eating disorder (ED) and gambling disorder (GD) patients.

Methods: The sample included 301 clinical cases (135 ED and 166 GD), diagnosed according to DSM-5 criteria, and 152 healthy controls $(\mathrm{HC})$ recruited from the general population.

Results: Food addiction was more prevalent in patients with ED, than in patients with GD and $\mathrm{HC}(77.8,7.8$, and 3.3\%, respectively). Food addiction severity was associated with higher BMI, psychopathology and specific personality traits, such as higher harm avoidance, and lower self-directedness. The psychometrical properties of the Spanish version of the YFAS 2.0 were excellent with good convergent validity. Moreover, it obtained good accuracy in discriminating between diagnostic subtypes.

Conclusions: Our results provide empirical support for the use of the Spanish YFAS 2.0 as a reliable and valid tool to assess food addiction among several clinical populations (namely ED and GD). The prevalence of food addiction is heterogeneous between disorders. Common risk factors such as high levels of psychopathology and low self-directedness appear to be present in individuals with food addiction.

Keywords: eating disorders, food addiction, gambling disorder, psychometric properties, validation, YFAS 2.0 


\section{INTRODUCTION}

Similarities in the biological and psychological factors involved in substance abuse and pathological overeating have led some researchers to postulate that addictive processes may underlie excess food consumption (1-3). Studies have shown that the neural reward centers triggered by addictive substances (such as alcohol or drugs), or behavioral addictions, can also be activated by highly palatable food (4-11). Similar to drugs of abuse, the intake of macronutrient-rich foods may increase extracelluar dopamine in neural regions implicated in reward and motivation, thereby increasing the likelihood of reward-driven eating in the absence of homeostatic need (12-15). Likewise, there is evidence that repeated exposure to sugar-sweetened beverages can lead to frontostriatal adaptations and behavioral disinhibition (16). Patients with substance use disorders and behavioral addictions also report symptoms that are also often found in the context of eating disorders (EDs) or in individuals with excess weight. For example, some individuals report that they compulsively consume highly palatable foods despite trying to cut down on food intake or that they experience loss of control once they begin eating certain foods (17). Strong cravings for foods despite feeling full and spending a disproportionate amount of time to obtain food are also common occurrences in some ED patient populations $(18,19)$. Most importantly, people who present these symptoms continue overeating even though the consequences of excess food intake may cause significant functional impairment in the physical, personal and/or social domains of their life (20). These behaviors can all be considered within the context of the impulsive/compulsive spectrum (21), though few studies to date have placed food addiction within this model.

The Yale Food Addiction Scale (YFAS) (22) was the first validated instrument to measure addictive-like eating behavior, commonly referred to as food addiction. This instrument was based on the Diagnostic and Statistical Manual of Mental Disorders (DSM-IV-TR) (23) criteria for substance dependence and was adapted to the context of food consumption. Multiple studies using this questionnaire have verified its psychometric soundness and validity, and empirical data have linked high symptom count on the YFAS to: (a) eating related problems, such as obesity, binge eating disorders, food cravings and poor response to bariatric surgery $(18,24-27)$; and (b) altered neural response (28-30).

The prevalence of food addiction based on YFAS criteria has been found to range from 11 to $40 \%$, depending on multiple factors such as the sample origin, participants' age (higher prevalence for middle-aged and older samples), sex (higher incidence in women), or lower socioeconomic level $(18,31-$ 34). In addition to food addiction being associated with obesity and binge eating disorder $(28,35,36)$, food addiction has also been observed in some normal-weight individuals who exhibit bulimic behavior (37). Levels of food addiction symptomatology appear to respond to psychological interventions, with one study finding that food addiction levels reduced after a short-term intervention in patients with bulimia nervosa (38). Interestingly, recent research has also linked food addiction symptomatology to gambling disorder (GD), suggesting that these two conditions may share common risk factors $(19,39,40)$. Still, there is lack of consensus within the scientific community and among clinicians regarding the proper operational definition of food addiction (41-44). Some researchers have posited that "eating addiction" rather than food addiction might be a more accurate designation due to the fact that evidence regarding the addictive properties of specific foods is scarce (45).

The YFAS 2.0 was recently developed (46) to coincide with the new DSM-5 substance-related and addictive disorders (SRAD) criteria (47). The objective of these SRAD criteria is to assess a recurrent pattern of abusive consumption that leads to clinically significant distress. It includes core symptoms such as cognitive distortions, craving, abstinence and tolerance (47). In order to maintain consistency with the DSM-5 model of addiction and to make certain that the YFAS 2.0 reflected these changes, the updated scale added items regarding craving, merged abuse and dependence criteria, and used a diagnostic continuum of severity. Results obtained in the original validation sample of 550 participants showed that the YFAS 2.0 had high internal consistency, and convergent and discriminant validity (high scores on the questionnaire were strongly linked to obesity and binge eating problems) (46). This scale has also been adapted and validated for German, Italian and French populations (48-50).

The food addiction construct, therefore, seems to share clinical characteristics with other addiction types, both substance and behavioral addictions, as well as with eating disorders $(45,51)$. However, there is a shortage of studies that aim to establish in depth a clear phenotype of these clinical populations, evaluating them together and comparing them with the general population. In order to establish these phenotypes, it is essential to assess food addiction levels in these populations, as well as co-occurring personality traits and psychopathology, given that all these factors are essential in defining and treating these different disorders (52). For this reason, the aim of the current study was to explore the associations of food addiction with clinically relevant variables such as psychopathology, personality, and gender in a sample of patients with an eating disorder (ED), with gambling disorder (GD), and a healthy-weight control group (HC). Additionally, we sought to analyze the psychometric properties of the Spanish version of the YFAS 2.0.

\section{MATERIALS AND METHODS \\ Participants}

The sample was recruited between May 2016 and March 2017. The study sample included three groups: a group of $n=135$ treatment-seeking ED patients, a group of $n=166$ treatmentseeking GD patients and a HC group of $n=197$ individuals recruited from the general population. The participants in the ED and GD groups were consecutively recruited from the Eating Disorders Unit at Bellvitge University Hospital in Barcelona, Spain, and the Gambling Disorder Unit at the same hospital. Patients were diagnosed according to DSM-5 criteria (47) by licensed clinical psychologists and psychiatrists. Information regarding the treatment protocols used in the Eating Disorder and Behavioral Addiction Units are explained in JiménezMurcia et al. (53) and Fernández-Aranda and Turon (54). 
Participants in the HC group were recruited from the same university hospital setting to guarantee the equivalence of the geographical origin between study groups. Inclusion criteria for the clinical groups were (1) fulfilling DSM-5 criteria for GD or an ED; and, for all participants, (2) being between 18 and 65 years old. Exclusion criteria for all participants included: the presence of an organic mental disorder, intellectual disability, a neurodegenerative condition, such as Parkinson's disease, or an active psychotic disorder. For the HC group, a lifetime history of ED or GD was an exclusion criterion.

In the ED group, 26 participants met criteria for anorexia nervosa (AN, 19.3\%), 43 for bulimia (BN, 31.9\%), 29 for binge eating disorder (BED, 21.5\%), and 37 for other specified feeding eating disorder (OSFED, 27.4\%). In the GD group, 23 patients (13.9\%) had mild GD severity (4 or 5 DSM- 5 criteria), 51 patients (30.7\%) had moderate GD severity (6 to 7 DSM-5 criteria), and 92 subjects $(55.4 \%$ ) had severe GD severity (8 or more DSM-5 criteria).

Table 1 includes a description of the sample (sociodemographic and clinical measures) stratified by group.

\section{Instruments}

Yale Food Addiction Scale Version 2.0 (YFAS 2.0) (46)

This self-report questionnaire consists of 35 items scored on an eight-level Likert scale (from $0=$ never to $7=$ every day) and adapted to assess addictive eating behaviors based on DSM-5 SRAD criteria.

The validated Spanish version of the original YFAS demonstrated very good psychometric properties (55): excellent internal consistency for the one single dimension solution $(\alpha=0.95)$, good accuracy in differentiating between the sample origin (ED vs. controls: specificity equal to $97.6 \%$, sensitivity $=72.8 \%$ and area under receiver operating curve AUC $=0.90$ ), good discriminative capacity in screening for specific EDs, and convergent validity compared to external measures of negative affect and depression, general psychopathology, eating disorder severity, and body mass index.

The Spanish YFAS 2.0 includes additional questions that take into account DSM-5 SRAD criteria and follows the scoring guidelines used in the original validation of the YFAS 2.0. These scoring guidelines produces two measurements: (a) a continuous symptom count score that reflects the number of fulfilled diagnostic criteria (ranging from 0 to 11); and (b) a food addiction threshold based on the number of symptoms (at least 2) and self-reported clinically significant impairment or distress. This final measurement allows for the binary classification of food addiction (present vs. absent). Based on the revised DSM5 taxonomy, the YFAS 2.0 also provides severity cutoffs for patients who surpass the threshold for food addiction: mild (2-3 symptoms), moderate (4-5 symptoms), and severe (6-11 symptoms).

The YFAS 2.0 was translated into Spanish in accordance with the International Test Commission Guidelines for Translating and Adapting Tests (56). Bilingual clinical psychologists with extensive experience in the ED field translated the original English version into Spanish. This translated Spanish version was then back-translated by a native English speaker and any differences between both versions were discussed and resolved by consensus. The Spanish YFAS Version 2.0 was reviewed by two other Spanish-speaking clinical psychologists, who had not been involved in the back-translation procedure. This was done in order to confirm that the instrument was clear and understandable for younger populations.

\section{Eating Disorder Inventory-2 (EDI-2) (57)}

This multidimensional self-report questionnaire includes 91 items to assess cognitive and behavioral characteristics related to eating disorders: drive for thinness, body dissatisfaction, bulimia, ineffectiveness, perfectionism, interpersonal distrust, interoceptive awareness, maturity fears, asceticism, impulse regulation, and social insecurity. A global measure of ED severity can be obtained based on the sum of all the items on the scale. The Spanish validation of this questionnaire obtained excellent psychometrical properties as an external global measure of ED severity (58). Internal consistency for EDI-total scores was excellent in our sample $(\alpha=0.97)$.

\section{Diagnostic Questionnaire for Gambling Disorder According to DSM Criteria (59)}

This 19-item questionnaire assesses DSM-IV-TR (23) and DSM-5 (47) diagnostic criteria for GD. Convergent validity with external measures of gambling severity in the original validation was very good ( $r=0.77$ for the sample recruited in the general population and $r=0.75$ for gambling treatment group; (59). Internal consistency of the Spanish version of the questionnaire used in this work was also good ( $\alpha=0.81$ for the general population and $\alpha=0.77$ for gambling treatment samples; (60). Internal consistency for the study was $\alpha=0.76$. A global measure of GD severity can be obtained based on the sum of all the items on the scale.

\section{Temperament and Character Inventory-Revised (TCI-R) (61)}

This self-report questionnaire is designed to evaluate personality traits using 240-items on a five-level Likert scale. It is structured on seven primary personality dimensions: four temperamental factors (novelty seeking, harm avoidance, reward dependence and persistence) and three character dimensions (self-directedness, cooperativeness and self-transcendence). The validated Spanish version used in this study has shown very good internal consistency (Cronbach's alpha $\alpha$ mean value of 0.87 ) (62). Cronbach's alpha for the TCI-R in the study sample was good to excellent (between $\alpha=0.78$ for novelty seeking to $\alpha=0.89$ to persistence; see Table 1 for the $\alpha$-values obtained in each TCI-R scale).

\section{Symptom Checklist Revised (SCL-90-R) (63)}

This 90-item self-report questionnaire is widely used for the measurement of perceived psychopathology. It is structured on nine first-order dimensions: somatization, obsessive-compulsive, interpersonal sensitivity, depression, anxiety, hostility, phobic anxiety, paranoid ideation and psychoticism. A global severity index is also used as a global distress index (GSI scale). The Spanish validation of this instrument has shown a mean internal 
TABLE 1 | Sample description.

\begin{tabular}{|c|c|c|c|c|c|c|c|c|c|c|}
\hline & & \multicolumn{2}{|c|}{$\begin{array}{c}\text { Eating disorder patients } \\
\qquad n=135\end{array}$} & \multicolumn{2}{|c|}{$\begin{array}{l}\text { Gambling disorder patients } \\
\qquad n=166\end{array}$} & \multicolumn{2}{|c|}{$\begin{array}{c}\text { Healthy control participants } \\
\qquad n=152\end{array}$} & \multirow[b]{2}{*}{$x^{2}$} & \multirow[b]{2}{*}{$d f$} & \multirow[b]{2}{*}{$p$} \\
\hline & & $n$ & $\%$ & $n$ & $\%$ & $n$ & $\%$ & & & \\
\hline \multicolumn{11}{|l|}{ SEX } \\
\hline Females & & 121 & 89.6 & 12 & 7.2 & 124 & 81.6 & 263.5 & 2 & $<0.001$ \\
\hline Primary or less & & 28 & 22.2 & 80 & 52.6 & 0 & 0.0 & 133.6 & 4 & $<0.001$ \\
\hline Secondary & & 87 & 69.0 & 59 & 38.8 & 148 & 99.3 & & & \\
\hline University & & 11 & 8.7 & 13 & 8.6 & 1 & 0.7 & & & \\
\hline \multicolumn{11}{|l|}{ CIVIL STATUS } \\
\hline Single & & 90 & 71.4 & 80 & 52.6 & 144 & 98.0 & 82.30 & 4 & $<0.001$ \\
\hline \multirow[t]{2}{*}{ Employed } & & 92 & 75.4 & 97 & 63.8 & 100 & 75.2 & & & \\
\hline & $\alpha$ & Mean & $S D$ & Mean & $S D$ & Mean & $S D$ & $F$ & $d f$ & $p$ \\
\hline Age (years-old) & & 31.35 & 13.66 & 40.44 & 13.11 & 21.21 & 3.03 & 118.5 & $2 / 450$ & $<0.001$ \\
\hline Body mass index (BMl, kg/m²) & & 26.89 & 10.17 & 26.48 & 4.83 & 22.12 & 4.08 & 22.07 & $2 / 450$ & $<0.001$ \\
\hline ED severity: EDI-2 total score & 0.971 & 107.91 & 38.28 & - & - & 33.60 & 25.93 & 368.2 & $1 / 285$ & $<0.001$ \\
\hline GD severity: total DSM- 5 criteria & 0.756 & - & - & 7.46 & 1.49 & - & - & - & - & - \\
\hline SCL-90-R GSI score & 0.982 & 1.77 & 0.75 & 1.19 & 0.67 & 0.63 & 0.46 & 112.7 & $2 / 450$ & $<0.001$ \\
\hline TCI-R Novelty seeking & 0.776 & 99.62 & 16.75 & 112.56 & 12.82 & 99.30 & 12.16 & 44.00 & $2 / 450$ & $<0.001$ \\
\hline TCl-R Harm avoidance & 0.892 & 120.76 & 18.56 & 100.22 & 15.73 & 98.79 & 17.89 & 67.31 & $2 / 450$ & $<0.001$ \\
\hline TCI-R Reward dependence & 0.829 & 98.13 & 15.68 & 99.53 & 16.44 & 103.96 & 14.08 & 5.59 & $2 / 450$ & 0.004 \\
\hline
\end{tabular}

$S D$, standard deviation; $d f$, degrees of freedom; $\alpha$, Cronbach's alpha in the sample; -, The measure is not available for this group.

consistency of $\alpha=0.75$ (64). In this study, the GSI score was used as an external measure to assess the YFAS 2.0 convergent validity. Cronbach's alpha for this scale in the sample was excellent $(\alpha=0.98)$.

In addition to the assessment battery, ED and GD patients underwent a semi-structured face-to-face interview to obtain sociodemographic data (age, education level, employment status, and civil status) and other clinical measures (age of disorder onset and disorder duration). This interviewing process has been described previously $(53,54)$.

\section{Ethics}

This study was carried out in accordance with the latest version of the Declaration of Helsinki. The Ethics Committee of Bellvitge University Hospital (Barcelona, Spain) approved the study, and signed informed consent was obtained from all final participants.

\section{Data Analyses}

Data analyses were carried out with Mplus8 (65) and Stata15 (66). Confirmatory Factor Analysis (CFA) assessed the single factor solution for the YFAS 2.0, defining each criterion as categorically dichotomous, and using robust weighted least squared estimator (WLSMV) and delta parameterization. Following previous validation studies for the YFAS, the item measuring impairmentdistress was not considered in the CFA since this is a criterion of clinical significance as a whole. Due to the heterogeneity of the sample of the study, the invariance by group ( $\mathrm{HC}$, $\mathrm{ED}$, and GD) and sex (male and female) were tested by fitting CFA multi-group models. Goodness-of-fit was considered adequate according to Barrett (67): Root Mean Square Error of Approximation RMSEA $<0.10$, Bentler's Comparative Fit Index CFI $>0.90$, Tucker-Lewis Index TLI $>0.90$, and Weighted Root Mean Square Residual WRMR $<1$. Internal consistency was measured through Cronbach's alpha ( $\alpha$, considering $\alpha>0.80$ to be adequate).

In this study, different dimensional and categorical measures for the YFAS 2.0 were analyzed. Firstly, the YFAS 2.0 dimensional symptom count, which measures the 11 DSM-5 SRAD criteria (raw scores are in the range of 0-11). And second, the two categorical classifications based on the dimensional symptom 
count: (a) a threshold for food addition (present for individuals with at least 2 symptoms plus self-reported clinically significant impairment or distress, and absent for participants who did not meet these criteria); and (b) for patients who met food addiction threshold, a categorical variable classified food addiction severity (mild for participants with 2 or 3 symptoms, moderate for individuals with 4-5, and severe for patients with at least 6 symptoms).

The capacity of the dimensional YFAS 2.0 symptom count to discriminate between the groups was tested through analysis of variance (ANOVA), and the capacity of the YFAS 2.0 categorical classifications to discriminate between the diagnostic subtypes was tested through chi-square tests $\left(\chi^{2}\right)$.

The convergent validity of the YFAS 2.0 with external measures (BMI and EDI-2), personality (TCI-R) and psychopathology scores (SCL-90R GSI) was estimated through Pearson's correlation ( $r$, with $|r| \geq 0.30$ considered evidence of a relevant association; (68).

Receiver Operating Characteristics (ROC) methodology assessed the accuracy of the YFAS 2.0 to differentiate between the diagnostic subtypes (ED, GD, and $\mathrm{HC}$ ). ROC analysis is usually employed in clinical epidemiology and research areas to quantify the accuracy of screening tests and to differentiate between patient states (typically referred to as diseased and non-diseased) (69). The area under the ROC curve (AUC) was estimated as a global measure of the global accuracy-validity of the YFAS 2.0 across all the cutoff points, compared with the external standard of ED group vs. HC group. In these subsamples, the accuracy of food addiction threshold was estimated through the sensitivity (Se) and specificity (Sp) coefficients, and through the Cohen'skappa measuring the agreement with the external standard of this work ( $\kappa$, considering $\kappa>0.40$ to be moderate, $\kappa>0.60$ to be good, and $\kappa>0.80$ to be excellent) (70).

Other statistical analysis in the study included $\chi^{2}$ procedures to compare the proportions obtained for categorical variables, and ANOVA to compare means obtained for quantitative variables between groups. Estimation of effect size for proportion comparisons and mean comparison was based on Cohen-d coefficient, considering $|d|<0.20$ to be null effect size for, $|d|>$ 0.20 to be low effect size, $|d|>0.50$ to be fair-moderate effect size, and $|d|>0.80$ to be good-high effect size (68).

\section{RESULTS}

\section{Food Addiction Prevalence and Symptom Count Among the Groups}

Table 2 includes the distribution of the YFAS 2.0 symptom count in each group and a comparison between them. In the ED group, food addiction symptom count levels were higher in comparison to both GD and HC groups. GD patients obtained higher proportion rates compared to $\mathrm{HC}$ for some criteria (although effect sizes were low): consume more than planned, use despite the physical/emotional or interpersonal effects and failure in role obligations. The prevalence of participants who met the threshold for food addiction was statistically equal for HC and GD (3.3 and $7.8 \%$, respectively), and very low compared to the prevalence registered for the ED group (77.8\%). Considering the YFAS 2.0 symptom count, the means registered in the three groups were statistically different ( 0.84 for HC, 1.43 for GD and 6.76 for ED), with the effect size not being relevant when comparing $\mathrm{HC}$ with GD patients. Figure 1 contains the box-plots for the symptom count and the bar-charts for those who met the food addiction threshold.

\section{Food Addiction Categories and Relevant Clinical and Personality Measures}

The first part of Table 3 contains the capacity of the YFAS 2.0 screening threshold to discriminate the clinical measures used in the study, that is, the comparison of the mean clinical scores (BMI, EDI-2 total scores, SCL-90-R, and TCI$\mathrm{R}$ scores) between participants in the food addiction-present vs. absent binary scores. All the means registered in the food addiction $=$ positive/present screening were statistically different than those registered in the food addiction =negative/absent screening, except for in the personality traits novelty seeking, cooperativeness and self-transcendence. Means in the food addiction group were statistically higher for BMI, EDI-2, GSI and harm avoidance, and lower for reward dependence, persistence and self-directedness. The second part of Table 3 contains the means registered in the clinical measures of the study for the groups defined according to YFAS 2.0 food addiction severity levels (mild, moderate and severe). Food addiction with mild severity obtained lower scores than moderate and severe food addiction levels in BMI and the EDI-2 and GSI scales; mild food addiction also registered lower means compared to severe food addiction in harm avoidance and persistence traits.

\section{Associations Between the YFAS 2.0 Symptom Count Levels and External Measures}

Table 4 includes the correlation matrix estimating the associations between the YFAS 2.0 symptom count levels and the participants' age, BMI, and EDI-2 total scores, psychopathology (SCL-90-R GSI scale) and personality traits (TCI-R dimensions). These results indicate that YFAS 2.0 symptom count levels are positively related to BMI, ED severity, psychopathology (GSI index), and harm avoidance. However, a negative correlation between food addiction symptom count levels and selfdirectedness was found. No correlation between GD severity levels and food addiction severity was found.

\section{Accuracy of the YFAS 2.0 as a Screening/Diagnosis Tool}

The YFAS 2.0 symptom count obtained excellent accuracy in discriminating between $\mathrm{HC}$ and the $\mathrm{ED}$ group (results in the ROC analysis reported AUC $=0.904$ ). The YFAS 2.0 diagnosis also adequately differentiated between participants in the $\mathrm{HC}$ and ED subsamples $(\mathrm{Sp}=96.7 \%$, $\mathrm{Se}=77.8 \%$, and Cohen's kappa measuring agreement was $\kappa=0.75$ ). 
TABLE 2 | Capacity of the YFAS 2.0 measures to discriminate between groups.

\begin{tabular}{|c|c|c|c|c|c|c|c|c|c|c|c|c|}
\hline \multirow[b]{3}{*}{ YFAS 2.0 criteria } & \multicolumn{2}{|c|}{ ED } & \multicolumn{2}{|c|}{ GD } & \multicolumn{2}{|c|}{$\mathrm{HC}$} & \multicolumn{2}{|c|}{ ED vs. } & \multicolumn{2}{|c|}{ GD vs. } & \multicolumn{2}{|c|}{ GD vs. } \\
\hline & \multicolumn{2}{|c|}{$n=135$} & \multicolumn{2}{|c|}{$n=166$} & \multicolumn{2}{|c|}{$n=152$} & \multicolumn{2}{|c|}{$\mathrm{HC}$} & \multicolumn{2}{|c|}{$\mathrm{HC}$} & \multicolumn{2}{|c|}{ ED } \\
\hline & $n$ & $\%$ & $n$ & $\%$ & $n$ & $\%$ & $p$ & $|d|$ & $p$ & $|d|$ & $p$ & $|d|$ \\
\hline Consumed more than planned & 90 & 66.7 & 33 & 19.9 & 16 & 10.5 & $0.001^{*}$ & $1.41^{\dagger}$ & $0.021^{*}$ & 0.26 & $0.001^{\star}$ & $1.07^{\dagger}$ \\
\hline Unable to cut down-stop & 81 & 60.0 & 26 & 15.7 & 19 & 12.5 & $0.001^{*}$ & $1.14^{\dagger}$ & 0.419 & 0.09 & $0.001^{*}$ & $1.03^{\dagger}$ \\
\hline Great deal of time spent & 87 & 64.4 & 27 & 16.3 & 24 & 15.8 & $0.001^{*}$ & $1.15^{\dagger}$ & 0.908 & 0.01 & $0.001^{*}$ & $1.13^{\dagger}$ \\
\hline Important activities given up & 98 & 72.6 & 18 & 10.8 & 7 & 4.6 & $0.001^{*}$ & $1.95^{\dagger}$ & 0.053 & 0.24 & $0.001^{*}$ & $1.61^{\dagger}$ \\
\hline Use despite physic-em. effects & 90 & 66.7 & 20 & 12.0 & 8 & 5.3 & $0.001^{\star}$ & $1.66^{\dagger}$ & $0.039^{*}$ & 0.25 & $0.001^{*}$ & $1.35^{\dagger}$ \\
\hline Tolerance & 76 & 56.3 & 14 & 8.4 & 7 & 4.6 & $0.001^{*}$ & $1.36^{\dagger}$ & 0.170 & 0.16 & $0.001^{*}$ & $1.19^{\dagger}$ \\
\hline Withdrawal & 91 & 67.4 & 24 & 14.5 & 18 & 11.8 & $0.001^{*}$ & $1.38^{\dagger}$ & 0.491 & 0.08 & $0.001^{*}$ & $1.28^{\dagger}$ \\
\hline Craving & 82 & 60.7 & 25 & 15.1 & 6 & 3.9 & $0.001^{*}$ & $1.53^{\dagger}$ & $0.001^{*}$ & 0.39 & $0.001^{*}$ & $1.07^{\dagger}$ \\
\hline Failure in role obligation & 75 & 55.6 & 15 & 9.0 & 2 & 1.3 & $0.001^{*}$ & $1.51^{\dagger}$ & $0.002^{*}$ & 0.35 & $0.001^{*}$ & $1.15^{\dagger}$ \\
\hline Use despite interpers. effects & 64 & 47.4 & 23 & 13.9 & 9 & 5.9 & $0.001^{*}$ & $1.06^{\dagger}$ & 0.009 & 0.27 & $0.001^{*}$ & $0.78^{\dagger}$ \\
\hline Use physically hazardous situat. & 79 & 58.5 & 13 & 7.8 & 11 & 7.2 & $0.001^{*}$ & $1.30^{\dagger}$ & 0.841 & 0.02 & $0.001^{*}$ & $1.28^{\dagger}$ \\
\hline Impairment or distress & 112 & 83.0 & 15 & 9.0 & 7 & 4.6 & $0.001^{*}$ & $2.58^{\dagger}$ & 0.120 & 0.18 & $0.001^{\star}$ & $2.21^{\dagger}$ \\
\hline \multicolumn{13}{|l|}{ FOOD ADDICTION } \\
\hline Positive-present & 105 & 77.8 & 13 & 7.8 & 5 & 3.3 & $0.001^{*}$ & $2.33^{\dagger}$ & 0.080 & 0.20 & $0.001^{\star}$ & $2.00^{\dagger}$ \\
\hline \multicolumn{13}{|l|}{ aSEVERITY } \\
\hline Mild & 9 & 8.6 & 2 & 15.4 & 1 & 20.0 & 0.508 & 0.33 & 0.814 & 0.12 & 0.305 & 0.21 \\
\hline Moderate & 14 & 13.3 & 0 & 0 & 0 & 0 & & $0.55^{\dagger}$ & & 0.00 & & $0.55^{\dagger}$ \\
\hline Severe & 82 & 78.1 & 11 & 84.6 & 4 & 80.0 & & 0.05 & & 0.13 & & 0.17 \\
\hline YFAS continuous measure & Mean & $S D$ & Mean & $S D$ & Mean & $S D$ & $P$ & $|d|$ & $P$ & $|d|$ & $P$ & $|d|$ \\
\hline Food addiction symptoms & 6.76 & 3.75 & 1.43 & 2.50 & 0.84 & 1.86 & $0.001^{*}$ & $2.00^{\dagger}$ & $0.049^{\star}$ & 0.27 & $0.001^{*}$ & $1.67^{\dagger}$ \\
\hline
\end{tabular}

${ }^{a}$ Classification of severity levels of patients who met the criteria for food addiction.

$\mathrm{HC}$, healthy control; ED, eating disorder; GD, gambling disorder. ${ }^{*}$ Bold, significant comparison $\left(0.05\right.$ level); ${ }^{\dagger}$ Bold, effect size in the moderate $(|d|>0.50)$ to good $(|d|>0.80$ range).

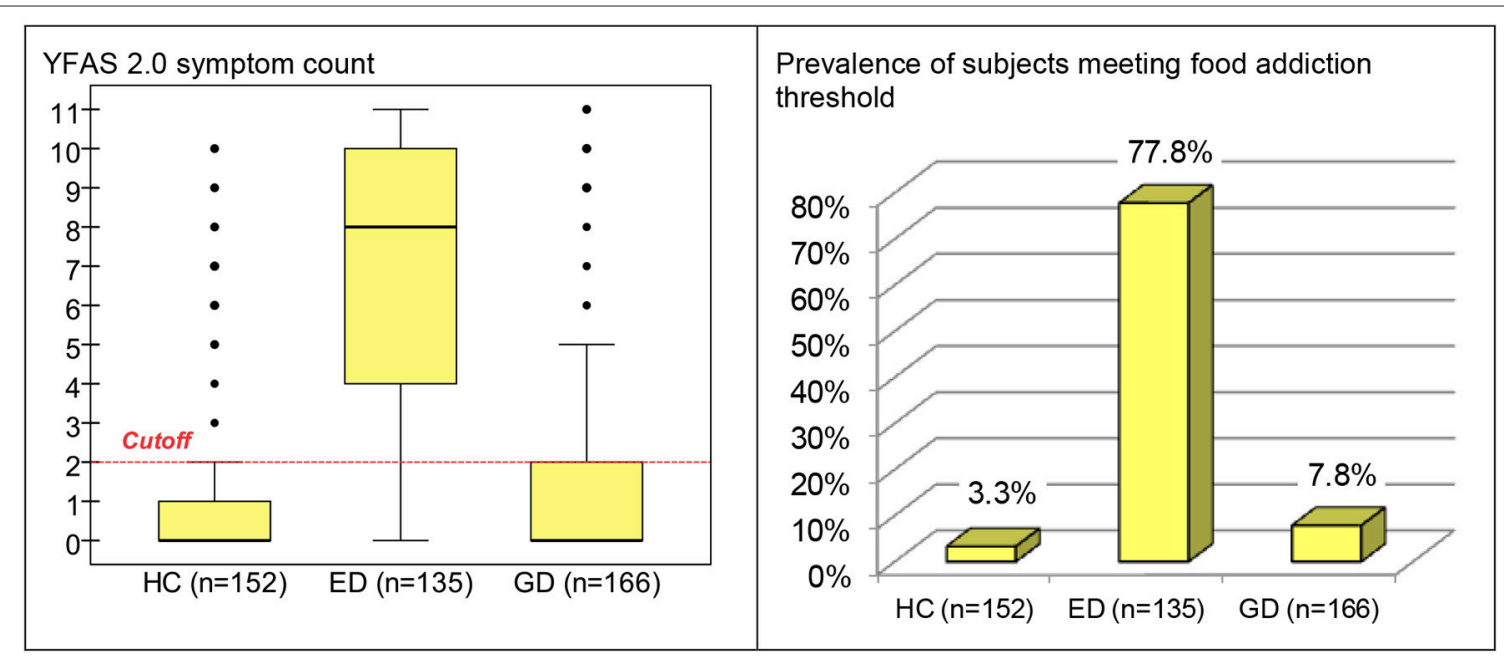

FIGURE 1 | Boxplot for YFAS 2.0 symptom count and bar-chart for prevalence of subjects meeting food addiction threshold (whole sample, stratified by group). HC, healthy control; ED, eating disorder; GD, gambling disorder.

\section{Confirmatory Factor Analysis}

Table S1 (supplementary material) contains the complete results for the CFA analysis. The single factor model obtained adequate fit in the whole sample: RMSEA $=0.034$, CFI $=0.998$, TLI $=$ 0.998 , and WRMSR $=0.723$. All the items reached very high loadings (above 0.80). The internal reliability coefficient was excellent $(\alpha=0.94)$. Multi-group analysis did not have a better fit to the data assessing the invariance of the questionnaire structure by group (HC-ED-GD: $\chi^{2}=129.04, d f=106, p=0.064$ ) and sex (women-men: $\chi^{2}=51.73, d f=53, p=0.524$ ). These findings 


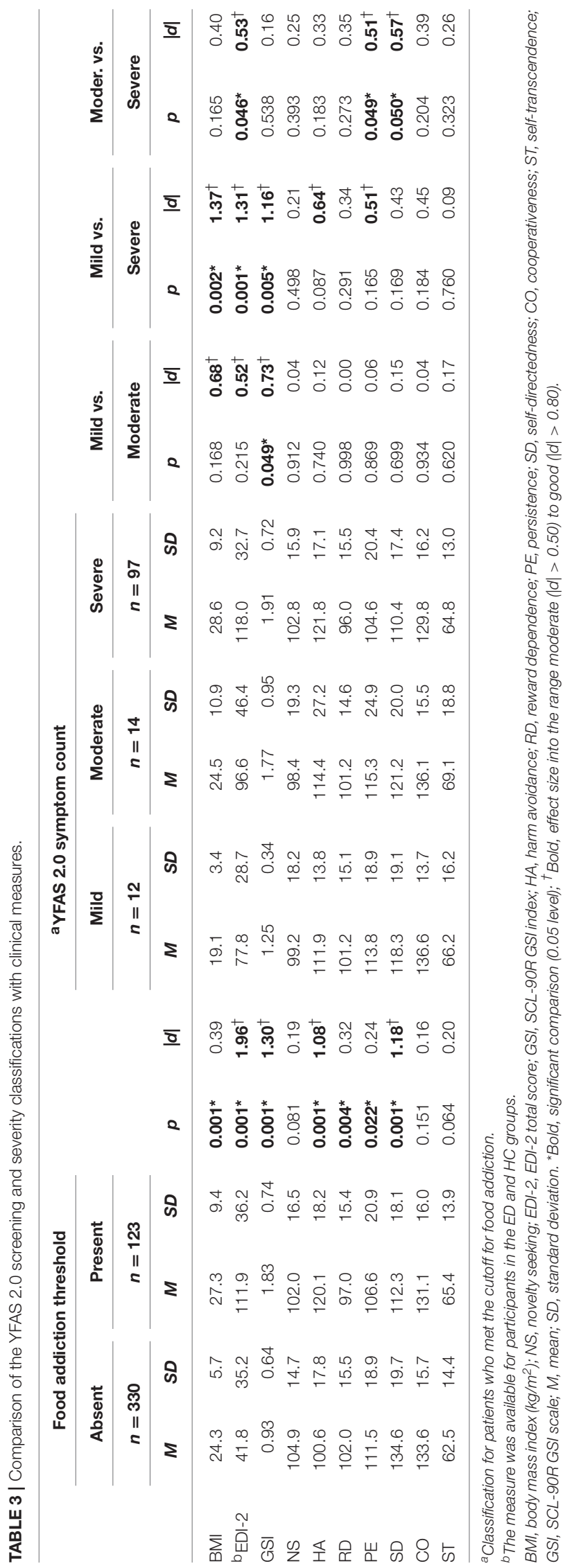

TABLE 4 | Pearson's correlation between the YFAS 2.0 symptom count with psychological measures.

\begin{tabular}{|c|c|c|c|c|}
\hline & $\begin{array}{c}\text { Total } \\
n=453\end{array}$ & $\begin{array}{c}\text { ED } \\
n=135\end{array}$ & $\begin{array}{c}\text { GD } \\
n=166\end{array}$ & $\begin{array}{c}\text { HC } \\
n=152\end{array}$ \\
\hline Age (years-old) & 0.121 & $0.250^{\dagger}$ & 0.018 & 0.135 \\
\hline Body mass index $\left(\mathrm{kg} / \mathrm{m}^{2}\right)$ & $0.345^{\dagger}$ & $0.345^{\dagger}$ & $0.342^{\dagger}$ & 0.098 \\
\hline SCL-90R GSI score & $0.565^{\dagger}$ & $0.288^{\dagger}$ & $0.318^{\dagger}$ & $0.619^{\dagger}$ \\
\hline TCl-R Novelty seeking & -0.034 & 0.189 & 0.029 & 0.033 \\
\hline TCI-R Harm avoidance & $0.464^{\dagger}$ & $0.253^{\dagger}$ & 0.124 & $0.280^{\dagger}$ \\
\hline TCI-R Reward dependence & -0.183 & $-0.247^{\dagger}$ & -0.057 & -0.104 \\
\hline TCl-R Persistence & -0.218 & $-0.251^{\dagger}$ & -0.160 & -0.026 \\
\hline TCI-R Self-directedness & $-0.531^{\dagger}$ & $-0.372^{\dagger}$ & $-0.334^{\dagger}$ & $-0.389^{\dagger}$ \\
\hline TCl-R Cooperativeness & -0.168 & -0.204 & $-0.302^{\dagger}$ & $-0.254^{\dagger}$ \\
\hline TCI-R Self-transcendence & 0.090 & 0.064 & 0.064 & 0.074 \\
\hline EDI-2 total score & & $0.368^{\dagger}$ & - & $0.658^{\dagger}$ \\
\hline GD: total DSM- 5 criteria & & - & 0.060 & - \\
\hline
\end{tabular}

$H C$, healthy control; ED, eating disorder; GD, gambling disorder; -, The measure is not available for the group. ${ }^{\dagger}$ Bold, effect size into the range moderate $(|r|>0.24)$ to good $(|r|$ $>0.30$ ).

suggested that the one dimensional structure was also adequate to represent the structure of the Spanish YFAS 2.0 for male and female, ED, GD, and, HC samples.

Table S2 (supplementary) includes the distribution of the YFAS 2.0 in the study, stratified by the diagnostic subtype and participants' sex. Analyses stratified for each group showed that no statistical differences emerged comparing the means of the YFAS 2.0 symptom count between men and women in the $\mathrm{HC}$ group $(F=1.12, d f=1 / 150, p=0.293)$ or in the $\mathrm{ED}$ group $(F=$ $0.11, d f=1 / 133, p=0.747)$, but it was when comparing sex in $\mathrm{GD}(F=4.14, d f=1 / 164, p=0.043)$.

Comparison of the YFAS 2.0 measures between ED subtypes obtained significant results for both the number of reported symptoms $(F=20.45, d f=3 / 131, p<0.001)$ and the presence of food addiction $\left(\chi^{2}=14.04, d f=3, p=0.003\right)$ (Figure 2). Pairwise comparisons for the YFAS 2.0 symptom count between groups indicated that no difference was present between OSFED and $\mathrm{AN}(T=0.35, d f=131, p=0.732)$, nor between $\mathrm{BN}$ and BED groups $(T=0.20, d f=131, p=0.839)$. However, OSFED patients endorsed lower symptom count levels than $\mathrm{BN}$ ( $T=$ 5.77, $d f=131, p<0.001)$ and BED patients $(T=5.41, d f=131$, $p<0.001$ ); whereas AN obtained lower symptom count levels than $\mathrm{BN}(T=5.56, d f=131, p<0.001)$ and BED patients $(T=$ $5.30, d f=131, p<0.001)$.

\section{DISCUSSION}

There has been growing scientific and clinical interest on whether parallels between the symptomatology present in individuals with substance abuse disorders and excessive food intake can be made (71). The food addiction construct has received increased clinical interest in recent years, although is not recognized as a DSM-5 condition $(72,73)$. The YFAS 2.0 is the only self-report questionnaire assessing food addiction, referring to addictive-like 


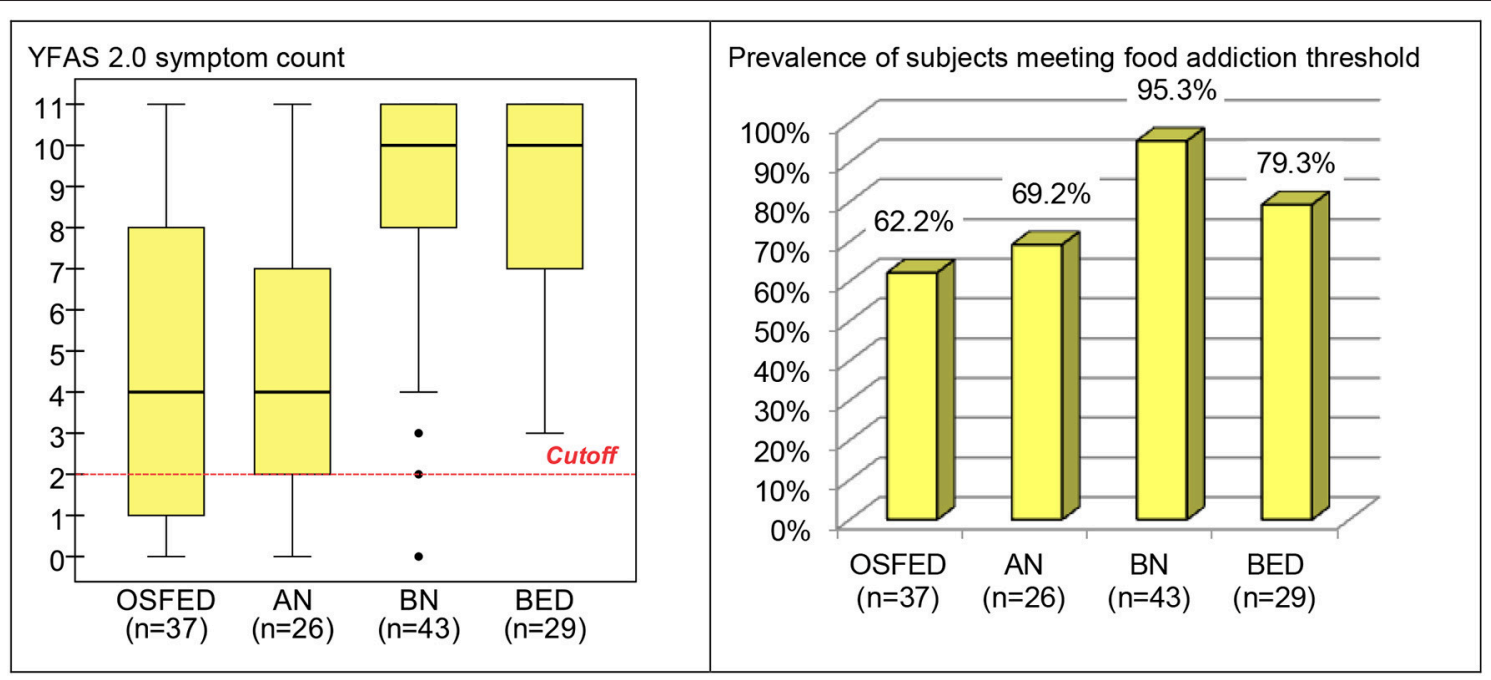

FIGURE 2 | Boxplot for the YFAS 2.0 symptom count and bar-chart for prevalence of subjects meeting food addiction threshold in the (ED subsample, stratified by ED subtype). OSFED, other specified feeding eating disorder; AN, anorexia nervosa; BN, bulimia nervosa; BED, binge eating disorder; ED, eating disorder.

eating, based on updated DSM-5 SRAD criteria (46). This tool has been validated in different languages, such as in German (48), Italian (50), and French (49). However, this is the first validation of a Spanish language version of the YFAS 2.0 that has been carried out to date. This study confirmed the sound psychometric properties of the Spanish YFAS 2.0. Additionally, we set out to assess the relevance of clinical measures and food-addictionrelated variables in a large sample including patients who met criteria for ED or GD, as well as a HC group.

In terms of prevalence, $3.3 \%$ of the participants of the $\mathrm{HC}$ group met criteria for the presence of food addiction. This finding is lower than the prevalence reported in the general population using previous versions of the YFAS (27) and in the development of this scale (46), but with similar values reported in previous version of the YFAS (2.4\% in HC) (55). Taking GD into account, $7.8 \%$ of the patients met criteria for the presence of food addiction. This prevalence is in accordance with a recent study obtaining similar values using the original YFAS (19). Finally, regarding ED samples, food addiction prevalence levels were comparable to those reported using the previous version of the YFAS (78\% of the ED participants in our study met the food addiction threshold; $(18,55)$. Additionally, the results of the current study indicate that the YFAS 2.0 has the discriminative capacity to differentiate between ED subtypes (lower food addiction levels were found in OSFED and AN compared to $\mathrm{BN}$ and $\mathrm{BED})$, which is also consistent with empirical data reported in previous studies $(24,55)$. In fact, in our study, the highest percentage of food addiction corresponded to $\mathrm{BN}$ group $(24,74)$. One can postulate that $\mathrm{BN}$ and $\mathrm{BED}$ patients endorsed higher food addiction severity levels due to the subjective feeling of loss of control and distress that are characterisitic bingeing episodes (75). The extent to which food addiction symptoms might be a premorbid condition of ED symptomatology, or just a consequent factor, could be not be explored with the present research design (51).
As in other studies, we found that higher scores in food addiction symptomatology were positively associated with BMI in ED and GD groups (24). We also found that food addiction prevalence was associated with higher BMI in subjects from the general population $(50,76)$. However, it must be stressed that not all obese or overweight individuals meet the criteria for "food addiction." For example, a study in a sample of obese adolescents found that just $38 \%$ of the sample met the threshold for food addiction (8). The prevalence found in our adult sample was very similar to that found in other studies (77). A recent metaanalysis also indicated that overweight/obese females aged over 35 years may be more predisposed to food addiction, as assessed by the YFAS (18). While some authors support the food addiction concept by arguing that it shares clinical and neurological traits with addictive disorders $(46,78)$, others state that it merely serves as an indicator of overeating severity (6).

Numerous similarities between ED and GD have been shown in terms of personality traits and neuropsychological factors $(39,79,80)$. Moreover, both disorders have been associated with the presence of food addiction. However, in the present study, food addiction symptom count levels were higher in the ED group compared to both GD and HC groups. Likewise, the prevalence of food addiction was significantly higher in the ED group in comparison with GD and HC groups. Although several studies have postulated that food addiction should be defined as a behavioral addiction due to the striking similarities between overeating and other behavioral addictions like GD $(81,82)$, our findings suggest that food addiction is strongly associated with ED pathology. However, it is important to bear in mind the gender differences in the clinical groups featured in this study; although GD is a condition that mostly affects males (83), when we consider only women with this condition, the rates of food addiction increase significantly (19).

The YFAS 2.0 threshold also demonstrated good capacity to discriminate between the clinical measures employed in the 
study. Overall, BMI and psychopathology levels were higher in the group with food addiction compared to those not food addiction meeting criteria. Specifically, participants who met the threshold for food addiction showed significantly higher scores in the GSI scale, indicating elevated general psychopathology levels. Significant differences were also found regarding some personality traits, participants who presented food addiction were characterized by higher levels in harm avoidance and lower self-directedness. These results are in the line with previous food addiction literature by our group indicating that individuals with food addiction, regardless of diagnoses tend to have lower levels of self-directedness $(19,84)$.

The findings of this study could be used to identify those individuals who best fit the food addiction model. However, more research is required to determine the efficacy of pharmacological and psychological approaches in individuals with food addiction. For example, naltrexone and bupropion have been used for chronic weight management in some obese adults, and, given that these medications are used in the treatment of other substance addictions, it could of interest to know whether patients who report more addictive-like symptoms respond differently (85). Psychological treatment could also have a positive impact on the cognitive processes involved in improving food addiction symptomatology.

\section{Limitations}

The findings of this study must be considered in the context of its limitations. First, the different groups were unbalanced in terms of sex and age. Future studies should aim to include more balanced samples and a control group that is more representative in terms of sociodemographical factors with respect to the clinical groups. Second, food addiction was assessed using a self-report measure which restricts the evaluation of other factors that may be interfering with the obtained results. Third, clinical groups are only constituted by treatment-seeking patients. Therefore, this population is not representative of all individuals with these problematic behaviors. Finally, in the present validation individuals without an ED but with overweight/obesity are underrepresented. Future food addiction studies should attempt to include subjects that reflect the general population.

\section{REFERENCES}

1. Carter A, Hendrikse J, Lee N, Ucel M, Verdejo-Garcia A, Andrews $\mathrm{Z}$, et al. The neurobiology of "Food Addiction" and its implications for obesity treatment and policy. Annu Rev Nutr. (2016) 36:105-28. doi: 10.1146/annurev-nutr-071715-050909

2. Schulte EM, Yokum S, Potenza MN, Gearhardt AN. Neural systems implicated in obesity as an addictive disorder: from biological to behavioral mechanisms. Prog Brain Res. (2016) 223:329-46. doi: 10.1016/bs.pbr.2015.07.011

3. García-García I, Horstmann A, Jurado MA, Garolera M, Chaudhry SJ, Margulies DS, et al. Reward processing in obesity, substance addiction and non-substance addiction. Obes Rev. (2014) 15:853-69. doi: 10.1111/obr.12221

4. Albayrak Ö, Wölfle SM, Hebebrand J. Does food addiction exist? A phenomenological discussion based on the psychiatric classification of substance-related disorders and addiction. Obes Facts (2012) 5:165-79. doi: $10.1159 / 000338310$

\section{AUTHOR CONTRIBUTIONS}

GM-B, TS, FF-A, RG, JM, AG, NM-B, ZA, CV-A, ML-M, CS-M, $\mathrm{CD}$, and $\mathrm{SJ}-\mathrm{M}$ designed the experiment based on previous results and the clinical experience of NA, MG-P, NR, IS, and FC. RG, GM-B, TS, FF-A, MN-A, and SJ-M conducted the experiment, analyzed the data, and wrote a first draft of the manuscript. SJ-M, TS, GM-B, RG, AG, CV-A, ML-M, and FF-A further modified the manuscript.

\section{FUNDING}

Financial support was received through the Ministerio de Economía y Competitividad (grant PSI2011-28349 and PSI201568701-R). This manuscript and research were supported by grants from Instituto de Salud Carlos III (ISCIII) (FIS PI14/00290, FIS PI17/01167) and cofounded by FEDER funds/European Regional Development Fund (ERDF), a way to build Europe. Aid from the Ministerio de Sanidad, Servicios Sociales e Igualdad (PR338/17-MSSSI) supported this project. FIS PI14/00290, FIS PI17/01167, and 18MSP001-2017I067 received aid from the Ministerio de Sanidad, Servicios Sociales e Igualdad. CIBER Fisiología Obesidad y Nutrición (CIBERobn) and CIBER Salud Mental (CIBERSAM), both of which are initiatives of ISCIII. GMB is supported by an AGAUR predoctoral grant (2018 FI_B2 00174), co-financed by the European Social Fund, with the support of the Secretaria d'Universitats i Recerca del Departament d'Economia i Coneixement de la Generalitat de Catalunya. CS-M is funded by a Miguel Servet contract from the Carlos III Health Institute (CP10/00604). ML-M was supported by a predoctoral Grant of the Ministerio de Educación, Cultura y Deporte (FPU15/02911). CV-A is supported by a predoctoral Grant from the Ministerio de Educación, Cultura y Deporte (FPU16/01453).

\section{SUPPLEMENTARY MATERIAL}

The Supplementary Material for this article can be found online at: https://www.frontiersin.org/articles/10.3389/fpsyt. 2018.00208/full\#supplementary-material

5. Leigh S-J, Morris MJ. The role of reward circuitry and food addiction in the obesity epidemic: AN update. Biol Psychol. (2016) 131:31-42. doi: 10.1016/j.biopsycho.2016

6. Davis C. Evolutionary and neuropsychological perspectives on addictive behaviors and addictive substances: relevance to the "food addiction" construct. Subst Abuse Rehabil. (2014) 5:129-37. doi: 10.2147/SAR. S56835

7. Markus CR, Rogers PJ, Brouns F, Schepers R. Eating dependence and weight gain; no human evidence for a "sugar-addiction" model of overweight. Appetite (2017) 114:64-72. doi: 10.1016/j.appet.2017. 03.024

8. Meule A. Back by Popular Demand: A narrative review on the history of food addiction research. Yale J Biol Med. (2015) 88:295-302.

9. Morin JP, Rodríguez-Durán LF, Guzmán-Ramos K, Perez-Cruz C, Ferreira G, Diaz-Cintra S, et al. Palatable hyper-caloric foods impact on neuronal plasticity. Front Behav Neurosci. (2017) 11:19. doi: 10.3389/fnbeh.2017. 00019 
10. Schulte EM, Avena NM, Gearhardt AN. Which foods may be addictive? The roles of processing, fat content, and glycemic load. PLoS ONE (2015) 10:e0117959. doi: 10.1371/journal.pone.0117959

11. Davis C. Compulsive overeating as an addictive behavior: overlap between food addiction and binge eating disorder. Curr Obes Rep. (2013) 2:171-8. doi: 10.1007/s13679-013-0049-8

12. Fortuna JL. The obesity epidemic and food addiction: clinical similarities to drug dependence. J Psychoactive Drugs (2012) 44:56-63. doi: 10.1080/02791072.2012.662092

13. De Jong JW, Vanderschuren LJMJ, Adan RAH. Towards an animal model of food addiction. Obes Facts (2012) 5:180-95. doi: 10.1159/000338292

14. Di Segni M, Patrono E, Patella L, Puglisi-Allegra S, Ventura R. Animal models of compulsive eating behavior. Nutrients (2014) 6:4591-609. doi: 10.3390/nu6104591

15. Iozzo P, Guiducci L, Guzzardi MA, Pagotto U. Brain PET imaging in obesity and food addiction: current evidence and hypothesis. Obes Facts (2012) 5:155-64. doi: 10.1159/000338328

16. Burger KS. Frontostriatal and behavioral adaptations to daily sugar-sweetened beverage intake: a randomized controlled trial. Am J Clin Nutr. (2017) 105:555-63. doi: 10.3945/ajcn.116.140145

17. MacLean PS, Blundell JE, Mennella JA, Batterham RL. Biological control of appetite: a daunting complexity. Obesity (2017) 25:S8-16. doi: 10.1002/oby.21771

18. Pursey KM, Stanwell P, Gearhardt AN, Collins CE, Burrows TL. The prevalence of food addiction as assessed by the yale food addiction scale: a systematic review. Nutrients (2014) 6:4552-90. doi: 10.3390/nu61 04552

19. Jiménez-Murcia S, Granero R, Wolz I, Baño M, Mestre-Bach G, Steward T, Agüera Z, Hinney A, Diéguez C, Casanueva FF, et al. Food addiction in gambling disorder: frequency and clinical outcomes. Front Psychol. (2017) 8:473. doi: $10.3389 /$ fpsyg.2017.00473

20. Nolan LJ. Is it time to consider the "food use disorder?" Appetite (2017) 115:16-8. doi: 10.1016/j.appet.2017.01.029

21. Oldham J. Impulsivity and Compulsivity. Washington, DC: American Psychiatric Press (1996).

22. Gearhardt AN, Corbin WR, Brownell KD. Preliminary validation of the Yale Food Addiction Scale. Appetite (2009) 52:430-6. doi: 10.1016/j.appet.2008.12.003

23. American Psychiatric Association. Diagnostic and Statistical Manual of Mental Disorders, Fourth Edition, Text Revision (DSM-IV-TR). Washington, DC: American Psychiatric Association (2000).

24. Gearhardt AN, Boswell RG, White MA. The association of "food addiction" with disordered eating and body mass index. Eat Behav. (2014) 15:427-33. doi: 10.1016/j.eatbeh.2014.05.001

25. Gearhardt AN, White MA, Masheb RM, Grilo CM. An examination of food addiction in a racially diverse sample of obese patients with binge eating disorder in primary care settings. Compr Psychiatry (2013) 54:500-5. doi: 10.1016/j.comppsych.2012.12.009

26. Gearhardt AN, White MA, Masheb RM, Morgan PT, Crosby RD, Grilo CM. An examination of the food addiction construct in obese patients with binge eating disorder. Int J Eat Disord. (2012) 45:657-63. doi: 10.1002/eat.20957

27. Meule A, Gearhardt AN. Five years of the Yale Food Addiction Scale: taking stock and moving forward. Curr Addict Rep. (2014) 1:193-205. doi: 10.1007/s40429-014-0021-z

28. Davis C. From passive overeating to "food addiction": a spectrum of compulsion and severity. ISRN Obes (2013) 2013:435027. doi: 10.1155/2013/435027

29. Davis C, Levitan RD, Kaplan AS, Kennedy JL, Carter JC. Food cravings, appetite, and snack-food consumption in response to a psychomotor stimulant drug: the moderating effect of "food-addiction". Front Psychol. (2014) 5:403. doi: 10.3389/fpsyg.2014.00403

30. Gearhardt AN, Yokum S, Orr PT, Stice E, Corbin WR, Brownell KD. Neural correlates of food addiction. Arch Gen Psychiatry (2011) 68:808-16. doi: 10.1001/archgenpsychiatry.2011.32

31. Berenson AB, Laz TH, Pohlmeier AM, Rahman M, Cunningham KA. Prevalence of food addiction among low-income reproductive-aged women. J Women's Health (2015) 24:740-4. doi: 10.1089/jwh.2014.5182
32. Ceccarini M, Manzoni GM, Castelnuovo G, Molinari E. An evaluation of the italian version of the Yale Food Addiction Scale in obese adult inpatients engaged in a 1-month-weight-loss treatment. J Med Food (2015) 18:1281-7. doi: 10.1089/jmf.2014.0188

33. Fattore L, Melis M, Fadda P, Fratta W. Sex differences in addictive disorders. Front Neuroendocrinol. (2014) 35:272-84. doi: 10.1016/j.yfrne.2014.04.003

34. Obregón A, Fuentes J, Pettinelli P. Association between food addiction and nutritional status in chilean college students. Rev Med Chil. (2015) 143:58997. doi: 10.4067/S0034-98872015000500006

35. N. Gearhardt A, A. White M, N. Potenza M. Binge eating disorder and food addiction. Curr Drug Abus Rev. (2011) 4:201-7. doi: 10.2174/1874473711104030201

36. Davis C, Curtis C, Levitan RD, Carter JC, Kaplan AS, Kennedy JL. Evidence that "food addiction" is a valid phenotype of obesity. Appetite (2011) 57:711-7. doi: 10.1016/j.appet.2011.08.017

37. Pursey KM, Collins CE, Stanwell P, Burrows TL. Foods and dietary profiles associated with "food addiction" in young adults. Addict Behav Rep. (2015) 2:41-8. doi: 10.1016/j.abrep.2015.05.007

38. Hilker I, Sánchez I, Steward T, Jiménez-Murcia S, Granero R, Gearhardt AN, et al. Food addiction in bulimia nervosa: clinical correlates and association with response to a brief psychoeducational intervention. Eur Eat Disord Rev (2016) 24:482-8. doi: 10.1002/erv.2473

39. Jiménez-Murcia S, Granero R, Moragas L, Steiger H, Israel M, Aymamí $\mathrm{N}$, et al. Differences and similarities between bulimia nervosa, compulsive buying and gambling disorder. Eur Eat Disord Rev. (2015) 23:111-8. doi: 10.1002/erv. 2340

40. Probst CC, van Eimeren T. The functional anatomy of impulse control disorders. Curr Neurol Neurosci Rep. (2013) 13:386. doi: 10.1007/s11910-013-0386-8

41. Avena NM, Bocarsly ME, Hoebel BG, Gold MS. Overlaps in the nosology of substance abuse and overeating: the translational implications of "food addiction". Curr Drug Abuse Rev. (2011) 4:133-9. doi: 10.2174/1874473711104030133

42. Rogers PJ. Food and drug addictions: Similarities and differences. Pharmacol Biochem Behav. (2017) 153:182-90. doi: 10.1016/j.pbb.2017.01.001

43. Smith DG, Robbins TW. The neurobiological underpinnings of obesity and binge eating: a rationale for adopting the food addiction model. Biol Psychiatry (2013) 73:804-10. doi: 10.1016/j.biopsych.2012.08.026

44. Ziauddeen $\mathrm{H}$, Fletcher PC. Is food addiction a valid and useful concept? Obes Rev. (2013) 14:19-28. doi: 10.1111/j.1467-789X.2012.01046.x

45. Hebebranda J, Albayraka Ö, Adanb R, Antel J, Dieguezc C, De Jongb J, et al. "Eating addiction", rather than "food addiction", better captures addictive-like eating behavior. Neurosci Biobehav Rev. (2014) 47:295-306. doi: 10.1016/j.neubiorev.2014.08.016

46. Gearhardt AN, Corbin WR, Brownell KD. Development of the Yale Food Addiction Scale version 2.0. Psychol Addict Behav. (2016) 30:113-21. doi: $10.1037 / \mathrm{adb} 0000136$

47. American Psychiatric Association. Diagnostic and Statistical Manual of Mental Disorders, Fifth Edition. Washington, DC: American Psychiatric Association (2013).

48. Meule A, Müller A, Gearhardt AN, Blechert J. German version of the Yale Food Addiction Scale 2.0: prevalence and correlates of "food addiction" in students and obese individuals. Appetite (2017) 115:54-61. doi: 10.1016/j.appet.2016.10.003

49. Brunault P, Courtois R, Gearhardt AN, Gaillard P, Journiac K, Cathelain $\mathrm{S}$, et al. Validation of the french version of the DSM-5 Yale Food Addiction Scale in a nonclinical sample. Can J Psychiatry (2017) 62:199-210. doi: 10.1177/0706743716673320

50. Aloi M, Rania M, Rodríguez Muñoz RC, Jiménez Murcia S, FernándezAranda F, De Fazio P, et al. Validation of the Italian version of the Yale Food Addiction Scale 2.0 (I-YFAS 2.0) in a sample of undergraduate students. Eat Weight Disord. (2017) 22:527-33. doi: 10.1007/s40519-017-0421-x

51. Treasure J, Leslie M, Chami R, Fernàndez-Aranda F. Are Trans diagnostic models of eating disorders fit for purpose? A consideration of the evidence for food addiction. Eur Eat Disord Rev. (2018) 26: 83-91. doi: 10.1002/erv.2578

52. Piccinni A, Marazziti D, Vanelli F, Franceschini C, Baroni S, Costanzo D, et al. Food addiction spectrum: a theoretical model from normality 
to eating and overeating disorders. Curr Med Chem. (2015) 22:1631-8. doi: 10.2174/0929867322666150227153015

53. Jiménez-Murcia $S$, Aymamí-Sanromà $M$, Gómez-Peña $M$, ÁlvarezMoya E, Vallejo J. Protocols de Tractament Cognitivoconductual pel Joc Patologic $i$ d'Altres Addiccions no Tòxiques. Barcelona: Hospital Universitari de Bellvitge, Departament de Salut, Generalitat de Catalunya (2006).

54. Fernández-Aranda F, Turon V. Trastornos Alimentarios: Guía Básica de Tratamiento en Anorexia y Bulimia. Masson, IA: Barcelona (1998).

55. Granero R, Hilker I, Agüera Z, Jiménez-Murcia S, Sauchelli S, Islam MA, et al. Food addiction in a Spanish sample of eating disorders: DSM-5 diagnostic subtype differentiation and validation data. Eur Eat Disord Rev. (2014) 22:389-96. doi: 10.1002/erv.2311

56. International Test Commission. International Test Commission Guidelines for Translating and Adapting Tests. (2010). Available online at: https://www. intestcom.org/files/guideline_test_adaptation.pdf

57. Garner DM. Eating Disorder Inventory-2. Odessa, TX: Psychological Assessment Resources (1991)

58. Garner DM. Inventario de Trastornos de la Conducta Alimentaria (EDI-2)Manual. Madrid: TEA (1998).

59. Stinchfield R. Reliability, validity, and classification accuracy of a measure of DSM-IV diagnostic criteria for pathological gambling. Am J Psychiatry (2003) 160:180-2. doi: 10.1176/appi.ajp.160.1.180

60. Jiménez-Murcia S, Stinchfield R, Álvarez-Moya E, Jaurrieta N, Bueno B, Granero R, et al. Reliability, validity, and classification accuracy of a spanish translation of a measure of DSM-IV diagnostic criteria for pathological gambling. J Gambl Stud. (2009) 25:93-104. doi: 10.1007/s10899-008-9104-x

61. Cloninger CR. The Temperament and Character Inventory-Revised. St. Louis, MO: Washington University (1999).

62. Gutiérrez-Zotes JA, Bayón C, Montserrat C, Valero J, Labad A, Cloninger CR, Fernández-Aranda F. Inventario del Temperamento y el Carácter-Revisado (TCI-R). Baremación y datos normativos en una muestra de población general. Actas Esp Psiquiatr. (2004) 32:8-15.

63. Derogatis L. SCL-90-R. Administration, Scoring and Procedures Manual. Baltimore, MD: Clinical Psychometric Research (1990).

64. Martinez-Azumendi O, Fernandez-Gomez C, Beitia-Fernandez M. Factorial variance of the SCL-90-R in a Spanish out-patient psychiatric sample. Actas Esp Psiquiatr. (2001) 29:95-102.

65. Muthén L, Muthén B. Mplus: Statistical Analysis with Latent Variables-User's Guide. Los Angeles, CA: Muthén \& Muthén (2007).

66. StataCorp. Stata Statistical Software: Release 15. (2017).

67. Barrett P. Structural equation modelling: adjudging model fit. Pers Individ Dif. (2007) 42:815-24. doi: 10.1016/j.paid.2006.09.018

68. Kelley K, Preacher KJ. On effect size. Psychol Methods (2012) 17:137-52. doi: $10.1037 / \mathrm{a} 0028086$

69. Zhou X, Obuchowski N, McClish D. Statistical Methods in Diagnostic Medicine. New York, NY: John Wiley and Sons, Inc (2002).

70. Altman D. Practical Statistics for Medical Research. London: CRC press (1991).

71. Mies GW, Treur JL, Larsen JK, Halberstadt J, Pasman JA, Vink JM. The prevalence of food addiction in a large sample of adolescents and its association with addictive substances. Appetite (2017) 118:97-105. doi: 10.1016/j.appet.2017.08.002

72. Tompkins Connie L, Laurent Jennifer, W. B. Food Addiction: A barrier for effective weight management for obese adolescents. Child Obes. (2017) 13:462-9. doi: 10.1089/chi.2017.0003
73. Burrows T, Skinner J, McKenna R, Rollo M. Food Addiction, Binge Eating Disorder, and Obesity: Is There a Relationship? Behav Sci. (2017) 7:54. doi: 10.3390/bs7030054

74. De Vries SK, Meule A. Food addiction and bulimia nervosa: new data based on the Yale Food Addiction Scale 2.0. Eur Eat Disord Rev. (2016) 24:518-22. doi: $10.1002 /$ erv. 2470

75. Wilfley DE, Citrome L, Herman BK. Characteristics of binge eating disorder in relation to diagnostic criteria. Neuropsychiatr Dis Treat. (2016) 12:2213-23. doi: 10.2147/NDT.S107777

76. Fernández-Aranda F, Steward T, Mestre-Bach G, Jiménez-Murcia, S Gearhardt A. Obesity and Food Addiction, Encyclopedia of Endocrine Diseases 2nd Edn. London: Academic Press (2018).

77. Meule A, Heckel D, Jurowich CF, Vögele C, Kübler A. Correlates of food addiction in obese individuals seeking bariatric surgery. Clin Obes. (2014) 4:228-36. doi: 10.1111/cob.12065

78. Gearhardt AN, Corbin WR, Brownell KD. Food addiction: an examination of the diagnostic criteria for dependence. J Addict Med. (2009) 3:1-7. doi: 10.1097/ADM.0b013e318193c993

79. Alvarez-Moya EM, Jiménez-Murcia S, Moragas L, Gómez-Peña M, Aymamí $\mathrm{MN}$, Ochoa C, et al. Executive functioning among female pathological gambling and bulimia nervosa patients: preliminary findings. J Int Neuropsychol Soc. (2009) 15:302-6. doi: 10.1017/S1355617709090377

80. Álvarez-Moya EM, Jiménez-Murcia S, Granero R, Vallejo J, Krug I, Bulik CM, et al. Comparison of personality risk factors in bulimia nervosa and pathological gambling. Compr Psychiatry (2007) 48:452-7. doi: 10.1016/j.comppsych.2007.03.008

81. Moreno C, Tandon R. Should overeating and obesity be classified as an addictive disorder in DSM-5? Curr Pharm Des. (2011) 17:1128-31. doi: 10.2174/138161211795656701

82. Yau YHC, Potenza MN. Gambling disorder and other behavioral addictions. Harv Rev Psychiatry (2015) 23:134-46. doi: 10.1097/HRP.0000000000000051

83. Jiménez-Murcia S, Fernández-Aranda F, Granero R, Menchón JM. Gambling in Spain: update on experience, research and policy. Addiction (2014) 109:1595-601. doi: 10.1111/add.12232

84. Wolz I, Hilker I, Granero R, Jiménez-Murcia S, Gearhardt AN, Dieguez C, et al. "Food Addiction" in patients with eating disorders is associated with negative urgency and difficulties to focuson long-term goals. Front Psychol. (2016) 7:61. doi: 10.3389/fpsyg.2016.00061

85. Tek C. Naltrexone HCI/bupropion HCI for chronic weight management in obese adults: Patient selection and perspectives. Patient Prefer Adher. (2016) 10:751-9. doi: 10.2147/PPA.S84778

Conflict of Interest Statement: The authors declare that the research was conducted in the absence of any commercial or financial relationships that could be construed as a potential conflict of interest.

Copyright (c) 2018 Granero, Jiménez-Murcia, Gearhardt, Agüera, Aymamí, Gómez-Peña, Lozano-Madrid, Mallorquí-Bagué, Mestre-Bach, Neto-Antao, Riesco, Sánchez, Steward, Soriano-Mas, Vintró-Alcaraz, Menchón, Casanueva, Diéguez and Fernández-Aranda. This is an open-access article distributed under the terms of the Creative Commons Attribution License (CC BY). The use, distribution or reproduction in other forums is permitted, provided the original author(s) and the copyright owner are credited and that the original publication in this journal is cited, in accordance with accepted academic practice. No use, distribution or reproduction is permitted which does not comply with these terms. 